\title{
AÇÃO AFIRMATIVA PARA A MULHER NEGRA BRASILEIRA: UM NOVO OLHAR PELA PERSPECTIVA DE GÊNERO
}

\section{AFFIRMATIVE ACTION FOR BRAZILIAN BLACK WOMEN: A NEW VISION THROUGH GENDER PERSPECTIVE}

\author{
Flávia Helena Santos da Silva* \\ Maria Geralda De Miranda** \\ Patrícia Maria Dusek ${ }^{* * *}$ \\ Kátia Eliane Santos Avelar***
}

\begin{abstract}
Resumo: Aborda-se neste artigo, a partir de pesquisas bibliográfica e documental, a eficácia das políticas de discriminação positiva ${ }^{1}$ na sociedade e na economia brasileira atual, em seu aspecto racial e de gênero. $O$ cerne da questão funda-se em saber qual foi o balanço das ações afirmativas na experiência brasileira, após a sua implementação? Como estariam os indivíduos, em especial as mulheres negras, no contexto atual? Teriam essas políticas públicas cumprido o seu papel? Conclui-se que é inegável o avanço da sociedade brasileira com a adoção das ações afirmativas voltadas para os negros, entretanto, o assunto é complexo por sua múltipla dimensão histórico político-social e econômica, uma vez que o racismo é uma tendência presente em sociedades que adotaram a escravidão e que o desafio é dar continuidade focalizando de forma mais objetiva as desigualdades oriundas, simultaneamente, de raça e gênero.
\end{abstract}

\footnotetext{
*Mestranda em Desenvolvimento Local pelo Centro Universitário Augusto Motta - UNISUAM. Possui Pós-Graduação em Direito Civil e Processo Civil pelo Centro Universitário Augusto Mota - UNISUAM e Graduação em Direito pelo Centro Universitário da Cidade (2004).

** Mestre em Literatura Comparada com ênfase nos estudos culturais pela Universidade Federal Fluminense (UFF) e Doutora em Letras com ênfase em estudos pós-coloniais, também pela UFF. Professora do Programa de Pós-Graduação em Desenvolvimento Local, do Centro Universitário Augusto Motta, UNISUAM.

*** Pós Doutora pela Universitá di Pisa (2015). Doutora em Direito pela Universidade Veiga de Almeida (2014). Mestre em Direito pela Universidade Cândido Mendes, onde também obteve o título de graduação na mesma área. Especialista em Direito pela EMERJ. Pesquisadora e membro da Comissão de Pesquisa da Universidade Castelo Branco - UCB. Parecerista ad hoc de Revistas Científicas. Professora da Universidade Castelo Branco e do Centro Universitário de Barra Mansa. Articulista, palestrante e conferencista bilíngue em eventos nacionais e internacionais.

**** Possui graduação em Farmácia e Bioquímica pela Universidade Federal de Juiz de Fora (1993), Mestrado em Ciências Biológicas pela Universidade Federal do Rio de Janeiro (UFRJ) (1996) e Doutorado em Ciências também pela Universidade Federal do Rio de Janeiro (2002). Atualmente é coordenadora do Laboratório de Referência Nacional para Leptospirose do Instituto Oswaldo Cruz (FIOCRUZ). Professora Titular e Pesquisadora do Programa de Pós-Graduação Profissional Interdisciplinar em Desenvolvimento Local do Centro Universitário Augusto Motta (UNISUAM). Pesquisadora da Universidade Santa Úrsula.

${ }^{1}$ Discriminação Positiva, ou Ação afirmativa, consiste em dar tratamento preferencial a um grupo historicamente discriminado, impedindo assim que o princípio da igualdade formal, expresso em leis neutras que não levam em consideração os fatores de natureza cultural e histórica, funcione na prática como mecanismo perpetuador da desigualdade. (MELLO, 1993).
} 
Palavras-Chave: Racismo. Sexismo. Políticas públicas.

Abstract: This article discusses the effectiveness of the policies of positive discrimination in society and in the current Brazilian economy, in its racial and gender aspects, based on bibliographic and documentary research. The core of the question is founded on what was the balance of affirmative actions in the Brazilian experience, after its implementation? How would individuals, especially black women, be in the current context? Would they have these public policies fulfilled their role? It is concluded that the advancement of Brazilian society with the adoption of affirmative actions directed towards blacks is undeniable, however, the subject is complex due to its multiple political-social and economic historical dimension, since racism is a trend present in Societies that have adopted slavery and that the challenge is to continue focusing more objectively on the inequalities arising, simultaneously, of race and gender.

Keywords: Racism. Sexism. Public policy. 


\section{INTRODUÇÃO}

Para uma melhor compreensão, o estudo foi dividido em três partes. $\mathrm{Na}$ primeira etapa, o texto se remete ao papel da escrava negra na sociedade brasileira, desde a época colonial, suas mazelas e sua importância para a economia, pois se entende que a colonização não só pretendia expandir o mercado, como também afetou o comportamento e o pensamento da vida dos povos colonizados, acarretando a desigualdade, e a perpetração do racismo.

$\mathrm{Na}$ segunda parte do artigo, discutem-se os Direitos Humanos em contraposição ao racismo e ao sexismo. Neste tópico, será apresentado os fundamentos e reflexos do racismo, também pela ótica de gênero, perpassando pelas suas consequências, na educação e no trabalho (demostrado através de pesquisa dos órgãos do IPEA, DIEESE e a ONU), bem como o que a desigualdade das oportunidades pode acarretar, em termos de Índice de Desenvolvimento Humano (IDH) que, consequentemente, priva o indivíduo da liberdade plena, como mostrado por Sen (2010), que resulta o subdesenvolvimento do país.

$\mathrm{Na}$ terceira parte, observa-se que a questão racial sempre provocou discussões na sociedade. Percebe-se que apesar de o legislador e organismos internacionais de direitos humanos criarem instrumentos para eliminação do racismo, tais ações não foram suficientes para evitar a forma de intolerância, o que propiciou o nascimento das ações afirmativas, que no Brasil, em seu aspecto racial, gerou muitas dúvidas e críticas.

\section{PAPEL ECONÔMICO DA ESCRAVA NEGRA NA SOCIEDADE BRASILEIRA}

Pode-se dizer que os escravos negros, na época colonial, ficavam responsáveis por todos os serviços (urbanos, domésticos ou rurais) e dificilmente conseguiam juntar dinheiro suficiente para comprar sua alforria.

Acrescente-se ao argumento que o escravo urbano gozava de uma situação superior ao do campo. As possibilidades que tinham de conseguir a alforria eram maiores, suas condições de saúde eram melhores, pois estavam mais próximos dos olhos da lei. 
No que concerne as escravas, trabalhavam na lavoura e outras, como, por exemplo, no Rio de Janeiro, no século XIX, eram conhecidas como "escravas de ganho", isto é, quituteiras, que vendiam livremente suas mercadorias pelas ruas, para obter o próprio sustento, e o de seus senhores. Algumas desempenhavam o trabalho doméstico: cuidavam da família do senhor, e também serviam como objeto sexual. Sua situação, como a do homem negro, esteve determinada pela condição de coisa. E ainda possuía a função biológica de reprodução a fim de aumentar a mão de obra da produção.

Os escravos facilmente adquiriam sua liberdade quando se achavam inutilizados, incapazes de produzir, representando para o senhor um ônus. E apesar de publicações de algumas leis como do Ventre Livre e a dos Sexagenários, poucos efeitos produziam, pois, a primeira, apesar de o filho do escravo nascer livre, geralmente quando recém-nascido, ficava atrelado à mãe, e acabavam ficando sob as ordens do seu senhor, isto quando não eram retirados de sua genitora e vendidos como escravos. Já a segunda lei, em verdade, acabou por eximir o senhor de sua responsabilidade para com o velho negro, excluindo-Ihe a obrigação de conceder abrigo e vestuário (SILVA; LAVORENTI; GENOFRE, 2003).

Nas fazendas, a lei maior era a do senhor do engenho, os negros só poderiam incorporar-se à nação segundo a vontade de seus senhores, ou por circunstâncias alheias (LOPES, 2002).

Observa-se também que, no período colonial, havia um impedimento sistemático de constituição da família negra. As causas da resistência em permitir a união entre os escravos baseava-se em razões econômicas e caracterizava-se pela dificuldade de se manter unidos marido, mulher e filhos em caso de vendas. Outro problema residia que os filhos de escravos eram propriedades do senhor. (DAVIS, 2016).

Por essa razão constatou Moutinho (2004, p. 147) que foi sobre os corpos negros de homens e, especialmente, das mulheres que, no processo da escravidão e pós-abolição, ergueram-se grandes empreendimentos da máquina colonizadora. No mesmo entendimento HOOKS (1995, p. 469) afirma que 
Mais que qualquer grupo de mulheres nesta sociedade, as negras têm sido consideradas "só corpo, sem mente". A utilização de corpos femininos negros na escravidão como incubadoras para geração de outros escravos era a exemplificação prática da ideia de que as "mulheres desregradas" deviam ser controladas. Para justificar a exploração masculina branca e o estupro das negras durante a escravidão, a cultura branca teve que produzir uma iconografia de corpos de negras que insistia em representá-las como altamente dotadas de sexo, a perfeita encarnação de um erotismo primitivo e desenfreado. (HOOKS, 1995, p. 469)

Semelhante ao entendimento da autora acima, González (1979, p. 13) descreve que as imagens das negras estão vinculadas, quase sempre, aos estereótipos de servilismo profissional e sexual: "A mulher negra é vista pelo restante da sociedade a partir de dois tipos de qualificação": doméstica e mulata. A profissão de "mulata" é uma das mais recentes criações do sistema hegemônico no sentido de um tipo especial de "mercado de trabalho" (...) produto de exportação".

Assim, notou-se que a conjugação do racismo com o sexismo produziu e produz até os dias atuais em relação as mulheres negras um desdobramento negativo sobre as dimensões da vida, que refletem em rebaixamento de autoestima, menores índices de casamento, ocupações de menor prestígio e remuneração e vulnerabilidade à saúde.

\subsection{Direitos humanos versus racismo e sexismo: onde se encontra a mulher negra?}

Uma das heranças da escravidão foi o racismo. A influência da escravidão na sociedade brasileira não se apagou com o advento da abolição e deixou sequelas que se conservam até os dias atuais. Como bem observa Dovidio, Gaertner e Pearson (2016, p. 268), no que concerne ao racismo moderno, "o mesmo não desapareceu, apenas mudou suas principais manifestações".

Além disso, a ausência de políticas reparatórias após os anos de escravidão, manteve gerações de negros nos piores índices estatísticos de pobreza.

Convém salientar que foi implementada uma política imigratória no período da abolição, sob a justificativa da falta de mão de obra qualificada para o trabalho livre. Segundo Moura (2014), essa foi uma tentativa de branqueamento da população e de alijar os negros da sociabilidade nascente, pois nesse período já 
haviam se diversificado nos espaços de atuação, assim como suas capacidades de trabalho, junto com a modernização das cidades e a vinda das indústrias inglesas.

Nesse sentido, segundo Fernandes (1989, p.75), o racismo é requisito para formação da população trabalhadora que excede a capacidade de absorção do mercado, ou seja, põe-na numa condição de superexploração, que desdobra em desvalorização do trabalho em geral. Isto é, a mercadoria força de trabalho é explorada de forma desigual sob a estruturação de relações raciais, com exigências diferentes para trabalhador branco e negro: "(...) A desigualdade racial é uma das desigualdades estruturais da sociedade brasileira".

No mesmo entendimento, Sen (2010, p. 20-21) pontua que "a rejeição da liberdade de participar do mercado de trabalho é uma das maneiras de manter a sujeição e o cativeiro da mão de obra, e a batalha contra a privação de liberdade existente no trabalho adscritício".

Corrobora Albornoz (2012) que o trabalho não é só um dever, mas um direito, pois através dele o homem se faz, aparece, enquanto cria, entra em relação com os outros, com seu tempo, seu mundo; se torna reconhecido e deixa impressa no planeta em que vive a marca de sua passagem.

E o que dizer da mulher negra, como ficou sua situação na sociedade e sua condição de trabalho, após a abolição? Cabe afirmar que o homem negro sofre com o racismo; a mulher negra sofre com o racismo e o sexismo.

Davis $(2016$, p. 17) refere-se que a centralidade que o trabalho ocupa hoje na vida das mulheres negras reproduz um padrão original estabelecido no período da escravatura, pois eram vistas como unidades de trabalho tais como os homens negros, no entanto, sofriam também abuso sexual. Destaca que a origem da força dessas mulheres está nas suas experiências concretas como escravas. Foi um legado de tenacidade, resistência e insistência na igualdade sexual.

Segundo o censo demográfico realizado pelo Instituto Brasileiro de Geografia e Estatística (IBGE, 2010), o Brasil contava com uma população de quase 191 milhões de habitantes, dos quais cerca de 15 milhões se declararam como pretos (7,6\% do total) e 82 milhões com pardos ( $43,1 \%$ do total). E aproximadamente 50 milhões são mulheres negras. 
Dados do estudo Retrato das Desigualdades de Gênero e Raça, do Instituto de Pesquisa Econômica e Aplicada (IPEA, 2015) revelam que um dos indicadores selecionados é a taxa de analfabetismo, que vem caindo de maneira importante no Brasil nas últimas décadas, mas que ainda não atingiu os patamares ideais e, nesse caso, apresenta um diferencial racial importante: em 2015, entre as mulheres com 15 anos ou mais de idade brancas, somente 4,9\% eram analfabetas; no caso das negras, este número era o dobro, 10,2\%. Entre os homens, a distância é semelhante.

O estudo também apontou que apesar dos avanços nos últimos anos, com mais brasileiros e brasileiras chegando ao nível superior, as distâncias entre os grupos perpetuam-se. Entre 1995 e 2015, duplica-se a população adulta branca com 12 anos ou mais de estudo, de $12,5 \%$ para $25,9 \%$. No mesmo período, a população negra com 12 anos ou mais de estudo passa de 3,3\% para 12\%, um aumento de quase 4 vezes, mas que não esconde que a população negra chega somente agora ao patamar de vinte anos atrás da população branca;

Se no campo educacional, as mulheres encontram-se, em geral, em melhor posição que os homens, esta vantagem não se reflete no mercado de trabalho, onde a maior parte dos indicadores mostra uma hierarquia estanque, na qual o topo é ocupado pelos homens brancos e a base pelas mulheres negras.

No que concerne ao trabalho, o primeiro indicador examinado é a taxa de participação, que mostra a parcela da população em idade ativa (16 a 59 anos) que está trabalhando ou à procura de trabalho. Este é um indicador em que o viés de gênero é bastante claro: as barreiras para as mulheres entrarem no mercado de trabalho se mostram presentes, apesar dos avanços das décadas passadas. Os últimos vinte anos parecem indicar que as brasileiras atingiram um "teto" de participação difícil de ser ultrapassado. Entre 1995 e 2015, a taxa de participação feminina pouco oscilou em torno dos $54-55 \%$, não chegou a $60 \%$. Isto significa que quase metade das brasileiras em idade ativa está fora do mercado de trabalho. 0 percentual masculino chegou a $85 \%$ e vem caindo, tenho alcançado menos de $78 \%$ no último ano da série. (IPEA, 2015)

Aquelas que se lançam no mercado de trabalho muitas vezes se deparam 
com a barreira de encontrar posição. Essa é uma dificuldade maior para as mulheres que para os homens. Em 2015, a taxa de desocupação feminina era de 11,6\% enquanto a dos homens foi de $7,8 \%$. No caso das mulheres negras, a proporção chegou a $13,3 \%$ (a dos homens negros, 8,5\%). Os maiores patamares encontram-se entre as mulheres negras com ensino médio completo ou incompleto ( 9 a 11 anos de estudo): neste grupo, a taxa de desocupação em 2015 foi 17,4\% (IPEA, 2015).

Uma importante ocupação feminina continua sendo o emprego doméstico, ao lado do serviço público e do emprego com carteira de trabalho assinada, que cresceu mais fortemente nos últimos vinte anos (respondia por 24\% das ocupadas em 1995 e por $36 \%$ em 2015).

As curvas que ilustram a flutuação do rendimento médio do trabalho da população brasileira mostram uma queda na primeira década - entre 1995 e 2005 e um aumento na década seguinte, com uma nova redução nos anos finais, que correspondem ao início da atual crise econômica. As distâncias entre os quatro grupos populacionais não se alteram expressivamente ao longo do período. Apesar de, proporcionalmente, o rendimento das mulheres negras ter sido o que mais se valorizou (80\%), enquanto o dos homens brancos foi o que menos cresceu (11\%), é possível observar a manutenção da mesma ordem - homens brancos, mulheres brancas, homens negros, mulheres negras - do maior para o menor rendimento.

$O$ indicador da proporção da população sem renda própria ilustra uma dinâmica interessante ao longo das últimas décadas. Neste caso, o viés de gênero é bastante evidente, fazendo com que, entre as mulheres, seja muito maior a proporção de pessoas sem renda, o que está diretamente relacionado à menor participação feminina no mercado de trabalho. Percebe-se, no entanto, uma redução importante nessa proporção ao longo do período analisado: entre as mulheres negras, por exemplo, 46,7\% não possuíam renda própria em 1995, comparados a 27,3\% em 2015. Esta redução possivelmente se deve à ampliação do acesso a benefícios assistenciais especialmente por parte das mulheres. (IPEA, 2015)

O estudo é baseado na comparação entre os dados entre 1995 e 2015, analisando temas como chefia de família, mercado de trabalho, trabalho doméstico, distribuição de renda e uso do tempo. 
Já o Departamento Intersindical de Estatística e Estudos Socioeconômicos (2017) aponta que mulheres negras são as que mais sofrem por existir evidência da desigualdade de gênero somada à racial, mostra as condições socioeconômicas em que vivem, acrescentada da negação cotidiana, pelo racismo e sexismo.

No Brasil, além do racismo social, as mulheres negras sofrem com o racismo institucional, que inviabiliza o acesso aos instrumentos do Estado e dificulta 0 combate ao preconceito no país. Além disso, elas têm o pior acesso aos serviços públicos, tais como saúde, trabalho e educação (SANTOS, 2014).

Com base no mesmo estudo, as mulheres negras estão no índice de maior pobreza, possuem menor escolaridade e menor expectativa de vida. São trabalhadoras informais sem acesso à previdência, residentes em ambientes insalubres e responsáveis pelo cuidado e sustento do grupo familiar.

As empresas não contratam mulheres negras para cargos de representação, como direção, seja na área pública ou privada, apesar de competência ou mérito (ROCHA et al., 2014).

Indaga-se o que fazer para alterar as realidades demonstradas em estatísticas para promover a igualdade da população negra e em especial de mulheres negras?

Inicia-se o pensamento, em atenção à Constituição Federal de 1988, com seu arcabouço de direitos fundamentais, representa o eixo vetor de proteção aos Direitos Humanos. Essa concepção está claramente assentada em seu Título I (Dos Princípios Fundamentais) e II (Dos Direitos e Garantias Fundamentais).

Os direitos fundamentais da pessoa humana são os inerentes ao universo de sua personalidade e de seu patrimônio moral, ao lado daqueles que são imprescindíveis para garantir um patamar civilizatório mínimo inerente à sua centralidade na vida socioeconômica e na ordem jurídica (DELGADO; DELGADO, 2017, p. 33).

E qual seria a importância dos Direitos Humanos no caso em tela? Melhor explicação traz Sen (2011, p. 392), que explica que a expressão advém da invocação de "direitos inalienáveis" na Declaração de Independência americana e afirmações similares na declaração francesa sobre "os direitos do homem", no século XVIII, mas 
também a adoção da Declaração Universal dos Direitos Humanos pela ONU, em 1948. Inclui que sua existência configura-se em declarações éticas fortes sobre o que deve ser feito, independentes desse direito já serem legais.

Piovesan, Piovesan e Sato (2013, p. 300-301) afirmam que a ética emancipatória dos direitos humanos demanda transformação social, a fim de que cada pessoa possa exercer, em sua plenitude suas potencialidades, sem violência e discriminação. Neste sentido, merecem destaque as violações da escravidão, do nazismo, do sexismo, do racismo, da homofobia, da xenofobia e outras práticas da intolerância.

E enquanto padrão de humanidade e de reivindicação de ordem moral, se encontram em permanente processo de construção e reconstrução, podendo e devendo ser compreendido em múltiplas dimensões, respeitados seus movimentos dialéticos. Possui caráter indivisível, interdependente e inter-relacionado (DELGADO; DELGADO, 2017).

Baseado nos conceitos acima, vale dizer que se torna insuficiente tratar o indivíduo de forma genérica, geral e abstrata. Faz-se necessária a especificação do sujeito de direito, que passa a ser visto em suas peculiaridades e particularidades, 0 que exige uma resposta específica e diferenciada. Como, por exemplo, a população afrodescendente, as mulheres, as crianças e demais grupos. Ao lado do direito à igualdade, surge como o direito fundamental, o direito à diferença. Importa o respeito à diferença e à diversidade. $O$ caminho para o sucesso de ações afirmativas de raça e gênero seria a focalização na base de status social.

\section{UMA PERSPECTIVA DE PROMOÇÃO DE IGUALDADE ATRAVÉS DAS AÇÕES AFIRMATIVAS: UM CAMINHO POSSÍVEL PARA A MULHER NEGRA}

Há a consciência de que o rompimento da escravatura levou alguns grupos à discriminação e, consequente, exclusão social, sendo por isso, válida a ideia de políticas afirmativas, destinadas a grupos marginalizados pela ausência de riquezas adquiridas e capacidade técnica para o trabalho.

A adoção de ações afirmativas são imperativos de justiça social, a aliviar a carga de um passado discriminatório e a fomentar no presente e no futuro 
transformações sociais necessárias (PIOVESAN; PIOVESAN; SATO, 2013, p.311).

Distinguem-se das políticas governamentais antidiscriminatórias fundamentadas em leis de conteúdo meramente proibitivo por terem natureza multifacetária (RESKIN, 1997). Trocando-se a omissão pela atuação ativa, imperativa do Estado surgiram as ações afirmativas, concebidas, inicialmente, nos Estados Unidos da América, mas hoje já adotadas em vários países. Nessa nova postura, passa o Estado a levar em conta fatores como sexo, raça e a cor no momento de contratar seus funcionários ou de regular a contratação por outrem, ou ainda, no momento de oferecer as oportunidades de acesso aos estabelecimentos de educação, evitando que a discriminação, que tem um fundo histórico e cultural, continue a perpetuar as iniquidades sociais (RASMUSSEN, 2017).

Fraser (2000-2001, p. 55-56) destaca "a concepção bidimensional da justiça. Esta concepção trata da redistribuição e do reconhecimento como perspectivas e dimensões distintas da justiça. Sem reduzir uma à outra, abarca ambas em um marco mais amplo".

Preceitua a Convenção Internacional sobre a Eliminação de todas as Formas de Discriminação Racial, que: "qualquer doutrina de superioridade baseada em diferenças raciais é cientificamente falsa, moralmente condenável socialmente injusta e perigosa, inexistindo justificativa para a discriminação racial, em teoria ou prática, em lugar algum." (BRASIL, 1969).

De outro giro, sobre o aspecto de discriminação de gênero, Sen (2010, p. 246) chama atenção para a condição de agente das mulheres, uma vez que se caracterizam como agentes ativos de mudança: promotoras dinâmicas de transformações sociais que podem alterar a vida de mulheres e de homens. A condição de agente não pode desconsiderar a urgência de retificar muitas desigualdades que arruínam o bem-estar das mulheres e as sujeitam a tratamento desigual. Diz a importância do poder feminino que pode ter grande projeção sobre as forças e os princípios organizadores que governam as divisões dentro da família e na sociedade. (SEN, 2010, p. 249).

Esta mesma lógica inspirou a definição de discriminação contra a mulher, quando da adoção da Convenção sobre a Eliminação de todas as Formas de 
Discriminação contra a Mulher, pela ONU, em 1979, destinadas a acelerar a igualdade de fato entre homens e mulheres (BRASIL, 1979). As Recomendações Gerais nº 5 e 25 do Comitê sobre a Eliminação de Discriminação endossam a importância de tais ações, para que a mulher se integre na educação, economia, política e emprego. A Agenda 2030 estabelece como um de seus princípios-chave que:

\begin{abstract}
Ninguém deve ser deixado para trás. As diversas formas de manifestação do racismo fazem com que a discriminação racial seja outro fato estruturante das desigualdades sociais no Brasil. Assim sendo, as recomendações do Sistema ONU no Brasil: (i) haja um alinhamento entre a Agenda 2030 e os ODS com a Década Internacional de Afrodescendentes; (ii) e as ações voltadas à promoção de atenção integral de saúde das mulheres, educação, empoderamento político e econômico e enfrentamento à violência contra mulheres incluam estratégias de desconstrução do racismo para gerar impactos diferenciados para as mulheres em sua diversidade, especialmente negras e indígenas. (ONU, 2018, p. 19)
\end{abstract}

A Recomendação Geral n. 25 do Comitê sobre todas as formas de Discriminação Racial traz uma nova perspectiva: alia a perspectiva racial à de gênero. Entende que a discriminação racial atinge de forma diferenciada homens e mulheres. A discriminação pode dificultar o acesso de mulheres a informações em geral, bem como obstar a denúncia das discriminações e violências que vierem a sofrer. Visa monitorar como as mulheres que pertencem às minorias étnicas e raciais exercem seus direitos, avaliando a dimensão da discriminação racial a partir de uma perspectiva de gênero. (PIOVESAN; PIOVESAN; SATO, 2013).

As ações afirmativas, como, por exemplo, as cotas para universidade e para concurso público de cunho racial prevê reserva de vagas para negros(as) que se autodeclarem negros. Mesmo promovendo e melhorando as condições da população afrodescendente, a situação enfrentada pelas mulheres é notória, pois se encontram em desvantagem no mercado de trabalho e na educação. Faz-se necessário a alteração das políticas positivas, com base nos índices demonstrados nos últimos anos para que se possa modificar as condições que se encontram as mulheres negras atualmente.

Carneiro (2003) pontua que as discriminações podem ser consideradas de natureza quadriplicada: raça, classe social, gênero e intragênero, as quais impedem um tratamento mais humano à mulher negra, configurando um problema, cujo 
enfrentamento se faz urgente.

\section{CONSIDERAÇÕES FINAIS}

O artigo permitiu uma análise acerca da ação afirmativa para mulheres negras brasileiras. Esse assunto possibilitou uma maior compreensão sobre a realidade excludente, conforme demonstrado pelas bases de dados, como também demonstrou a importância de se discutir sobre a continuidade das políticas públicas, em especial as educacionais, as quais permitam incluir esses grupos marginalizados.

O estudo aponta a presença do racismo conjugado com o sexismo acerca do baixo número de representatividade negra feminina mesmo as que ascendem através de políticas públicas educacionais, mas quando vão para o mercado de trabalho não encontram, muitas vezes, posicionamento da profissão pela qual estudaram.

Percebeu-se que o presente ainda representa um resquício do passado marcado por explorações de um ser humano por outro e profundas desigualdades étnico-raciais, em especial para as mulheres negras.

Neste sentido, Davis (2016, p. 13) atribuiu à mulher negra um papel essencial, por se tratar de um grupo que, sendo o mais atingido pelas consequências de uma sociedade, foi obrigado a compreender, para além de suas opressões, a opressão de outros grupos.

No tocante à elaboração de políticas públicas, Sen $(2010$, p.349) ressalta que é importante não apenas avaliar as exigências de justiça e o alcance dos valores ao se escolherem os objetivos e as prioridades, mas também compreender os valores do público em geral, incluindo seu senso de justiça.

Assim, afirma-se que o Brasil admitiu a necessidade de reparar distorções ocasionadas pelo racismo. Faz-se necessário para suprir essa lacuna, considerar não só a exclusão pela raça como conjugar o gênero, bem como a participação de toda a sociedade para avaliação e acompanhamento dessas políticas positivas já implementadas.

Dessa forma, procurou-se demonstrar, neste artigo, a influência do racismo e sexismo para a mulher negra, seu papel histórico para a construção da sociedade 
brasileira, assim como a continuidade de ações afirmativas que apesar de seu conteúdo e avanços, atingiu minimamente no recorte gênero e raça baseada nas estatísticas pesquisadas. Espera-se a continuidade da promoção da igualdade dos grupos em desvantagem, para que se possa alcançar o que preceitua os Direitos Humanos em um Estado Democrático de Direito.

\section{REFERÊNCIAS}

ALBORNOZ, S. O que é trabalho. São Paulo: Brasilense, 2012.

BRASIL. Decreto no 65.810, de 8 de dezembro de 1969. Promulga a Convenção Internacional sobre a Eliminação de todas as Formas de Discriminação Racial.

Disponível em: https://www2.camara.leg.br/legin/fed/decret/1960-1969/decreto65810-8-dezembro-1969-407323-publicacaooriginal-1-pe.html. Acesso em: 8 mar. 2019.

BRASIL. Decreto no 4.377, de 13 de setembro de 2002. Promulga a Convenção sobre a Eliminação de Todas as Formas de Discriminação contra a Mulher, de 1979, e revoga o Decreto no 89.460, de 20 de março de 1984. Disponível em:

http://www.planalto.gov.br/ccivil_03/decreto/2002/D4377.htm. Acesso em: 8 mar. 2019.

CARNEIRO, S. Mulheres em movimento. Estudos avançados, São Paulo, v. 17, n. 49, p. 117-132, set./dez. 2003. Disponível em:

http://www.scielo.br/scielo.php?script=sci_arttext\&pid=S0103-40142003000300008. Acesso em: 15 nov. 2003.

DAVIS, A. Mulheres, Raça e Classe. São Paulo: Boitempo Editorial, 2016.

DELGADO, M; DELGADO.G. A reforma trabalhista no Brasil com os

comentários à lei 13.467/2017. São Paulo: LTR, 2017.

DEPARTAMENTO INTERSINDICAL DE ESTATÍSTICA E ESTUDOS SOCIOECONÔMICOS. Inserção da população negra nos mercados de trabalho metropolitanos. [S./]: Dieese, 2017. Disponível em: https://www.dieeses.org.br. Acesso em: 24 ago. 2018.

DOVIDIO, J. F.; GAERTNER, S. L.; PEARSON, A. R. Aversive racism and contemporany bias. In: SIBLEY, C.; BARLOW, F. (Ed.). The Cambridge Handbook of the Psychology of Prejudice. Cambridge: Cambridge University Press, 2016. p. 267294. Disponível em: https://doi.org/10.1017/9781316161579.012. Acesso em: 26 jun. 18. 
FERNANDES, F. O Significado do Protesto Negro. São Paulo: Cortez, 1989.

FRASER, N. Redistribuición, reconomecimiento y participación: hacia un concepto integrado de la justicia. [S./.]: Unesco: 2000-2011. Informe Mundial sobre la Cultura.

GONZÁLEZ, L. 0 papel da mulher negra na sociedade brasileira: uma abordagem político econômica. Los Angeles: [s.n], 1979.

HOOKS, B. Intelectuais Negras. Estudos Feministas, [s./.], n.2, p. 464-478, 1995.

IBGE. Pesquisa Nacional Por Amostra de Domicilio (PNAD), 2010. Rio de Janeiro: IBGE, 2010.

IPEA. Retrato das Desigualdades de Gênero e Raça. 2015. Disponível em: http://www.ipea.gov.br/retrato/. Acesso em 27. ago. 2018.

LOPES, J. R. de L. Desigualdades Jurídicas - povos indígenas, favelados e semterras. Boletim Científico Escola Superior do Ministério público da União), Brasília, ano I, n. 5, p. 69-86, out./dez. 2002.

MELLO, C. A. B. de. O Conteúdo Jurídico do Princípio da Igualdade. São Paulo: Revista dos Tribunais, 1993.

MOURA, C. Dialética Radical do Brasil Negro. 2.ed. São Paulo: Anita Garibaldi, 2014.

MOUTINHO, L. Razão, "cor" e desejo: uma análise comparativa sobre relacionamentos afetivo-sexuais "inter-raciais" no Brasil e na África do Sul. São Paulo: UNESP, 2004.

ONU. Direitos Humanos das Mulheres. A Equipe das Nações Unidas no Brasil. Jul. 2018. Disponível em: <https://nacoesunidas.org>. Acesso em: 27 ago. 2018.

PIOVESAN, F; PIOVESAN L.; SATO, P.K. Ações afirmativas no Brasil: desafios e perspectivas. In: Temas de Direitos Humanos. São Paulo: Saraiva, 2013.

RASMUSSEN, K. L. Affirmative Action, Historical Injustice, and The Concept of Beneficiaries. The Journal of political Philosophy, [S.I.], v. 25, n.1, p. 72-90, 2017.

RESKIN, B. Affirmative Action im Employment. Washington: American Sociological Association, 1997.

ROCHA, C.D. et al. O fenômeno teto de vidro na ascensão à posição hierárquica das mulheres no mercado formal: Barreiras. In: SIMPÓSIO DE EXCELÊNCIA EM GESTÃO 
E TECNOLOGIA, 11., 2014, Resende, RJ. Anais eletrônicos [...]. Disponível em: https://www.aedb.br/seget/arquivos/artigos14/38320405.pdf. Acesso em: 27 ago. 2018.

SANTOS, R. Cotas para Negros(as) em Concursos Públicos. 2014. Monografia (especialização em Gestão de Políticas Públicas em Gênero e Raça) - Faculdade de Educação, Universidade de Brasília, 2014.

SEN, A. Desenvolvimento como liberdade. São Paulo: Companhia das Letras, 2010.

SEN, A. A Ideia de Justiça. São Paulo: Companhia das Letras, 2011.

SILVA, J. G. da; LAVORENTI, Wilson; GENOFRE, Fabiano. LEIS Penais Anotadas. 4. ed. Campinas: Milenium, 2003. 